How adults with profound intellectual disabilities initiate interaction To be published in Sociology of Health and Illness Accepted 2016

Charles Antaki ${ }^{1}$, Rebecca J. Crompton ${ }^{2}$, Chris Walton ${ }^{3}$ and Mick Finlay 4 1

Dept. of Social Sciences

Loughborough University

Loughborough, LE11 3TU

UK

c.antaki@Lboro.ac.uk

2

Limehurst Academy

Bridge Street

Loughborough

LE11 1NH

r.j.crompton-10@alumni.lboro.ac.uk

3

Dept. of Psychology,

Lancaster University

Lancaster

LA1 4YF

c.walton@lancaster.ac.uk

4

Dept. of Psychology

Anglia Ruskin University

Cambridge

CB1 1PT

Mick.Finlay@anglia.ac.uk 
$\underline{\text { How adults with a profound intellectual disability initiate interactions }}$

\begin{abstract}
Using video records of everyday life in a residential home, we report on what interactional practices are used by people with severe and profound intellectual disabilities to initiate encounters. There were very few initiations, and all presented difficulties to the interlocutor; one (which we call "blank recipiency") gave the interlocutor virtually no information at all on which to base a response. Only when the initiation was of a new phase in an interaction already under way (for example, the initiation of an alternative trajectory of a proposed physical move) was it likely to be successfully sustained. We show how interlocutors (support staff; the recording researcher) responded to initiations verbally, as if to neurotypical speakers, but inappropriately for people unable to comprehend, or to produce well-fitted next turns. This misreliance on ordinary speakers' conversational practices was one factor that contributed to residents abandoning the interaction in almost all cases. We discuss the dilemma confronting care workers.
\end{abstract}

Whole text $=9,179$ words 
People diagnosed as having severe or profound intellectual disabilities (according to the American Psychological Association's DSM 5 (APA, 2013). or the World Health Organisation's ICD-10, WHO, undated) have very low IQ scores (if they can be assessed) and require substantial support in everyday activities. Since such individuals have little or no symbolic language, they face substantial and chronic problems in communication. From a sociological point of view, commentators since Oliver (1990), especially Coles (2001) and Goodley (2001) have argued that such difficulties not only limit the lifeopportunities of people with disabilities, but put in jeopardy their personhood and their place in the social world.

There is a large literature on how welfare practitioners (care workers, therapists and others) may arrange activities and schedules to encourage people with impairments to be active and engage in physical and social interaction (a practice often referred to as "Active Support"; for a recent overview, see Mansell and Beadle-Brown 2012). But our interest here is in the person's own efforts at initiating contact with others, or what might be treated as such initiation. The question we ask in this article is a specific one: how does a person with such disabilities gain a foothold in the social world by initiating contact with those around them? What practices can they deploy to get someone's attention, and engage in some sort of interaction?

\section{Research on the details of interaction}

Research into the interactional problems experienced by people with severe or profound intellectual disabilities (including those with congenital deafblindness; henceforth, for brevity, 'people with SPID') has tended to rely on counting gross categories of behaviour (e.g. Hodapp et al, 1989; Prain et al, 2010; Zilber et al, 1994) or, at a still further remove, the reports by third parties (e.g. family or care staff) on rating scales or in interview (e.g. Cascella, 2005; Forster \& Iacono, 2008; Porter et al, 2001; for a review of research methods see 
Hostyn \& Maes, 2009). Closely observed qualitative accounts with careful attention to the details of interaction, of the kind exemplified by the ethnomethodological work of Goode (1994), who engaged very closely with the embodied experience of children with multiple sensory and intellectual disabilities, is rare. Goode relied on audio recordings of his field observations, rather than video recordings of the scene; but interaction-based research that does use video has tended, with some exceptions (e.g. Finlay et al, 2008) to focus on people with less profound conditions (e.g. Ellertsen, 2014), and on the verbal behaviour of the people they interact with, especially their support workers and other professionals (e.g. Williams, 2011; Antaki, Finlay, Walton and Pate, 2008).

Research in schools and services for this group has generally found low levels of interaction and engagement, and has noted that the talk of supporters and teachers is often directive in nature and not adapted to the recipient's level of communication (e.g. McConkey et al, 1999; Prain et al, 2010; Zilber et al, 1994). When informants were offered (by Cascella, 2005) options as to what people with severe and profound IDs used in communication they reported reaching, body orientation, facial expression, vocalisations/sounds, eye gaze, leading a person, pushing away, head nods/shakes, single words and signs and electronic devices. Typical 'functions' (again, chosen by informants from check-list options) were to convey emotional state, make a choice or request, protest, greet, attract attention, initiate interaction, or name objects and people.

However, second-hand reports may gloss what happens in real time instances of such behaviours will often be ambiguous in their meaning, and supporters might disagree over what they signify (Grove et al, 1999; Porter et al, 2001; Zilber et al, 1994). Elements of 'good' interactions with people with severe and profound IDs which have been identified in the literature (e.g. Clegg et al, 1996; Detheridge, 1997; Forster \& Iacono, 2008; Hostyn \& Maes, 
2009;) include being sensitive to small changes in the other, joint activities (and hence attention), the ability of supporters to modify their usual behaviour (e.g. using mimicry and touch), perseverance in the face of low responsiveness, making assumptions about meaning, playfulness, routine/rituals, and verbal commentary on current activity.

Some authors have attempted to specify behaviours which can be taken to indicate intentionality (for a discussion of this concept see Grove et al, 1999), some of which can also be taken to identify initiations. For example, Cascella (2005) lists leading the other by hand, requesting items, actions or assistance, and directing staff actions. Bruce and Vargos (2007) suggest two essential features (attempt at establishing joint attention and expressing a message in a way that the other understands) and seven non-essential indictors (waiting for a response, persisting until a response is received, repeating or repairing when there is a misunderstanding, and showing pleasure or displeasure). Clearly these types of features rely on a good deal of interpretation and, as will be seen below, interlocutors often treat behaviours as initiations even in the absence of these indicators.

\section{Initiations}

Previous research on how people with ID engage in communication has operated, reasonably, from a common-sense understanding of what counts as taking part in an interaction. Hence the reliance of the kind of research mentioned above on straightforward categorical descriptions of behaviour.

But when it comes to initiating an interaction - doing what Sacks (1992 p 50) calls "pick-ups" to start what Goffman (1971) calls "direct engagement", rather than mere co-presence in a shared space - common-sense description conflates the contribution of different communicational elements produced by the initiator: speech, tone of voice, gaze, body posture, and so on. Moreover, it 
underplays the degree to which a communicative action requires a response from a recipient. Some actions may have the elements of an 'initiation', but not be responded to; and, conversely, some behaviour can lack any of these elements and yet be treated by a recipient as an initiation requiring a response.

To help us navigate these waters, we can turn to the conversation analytic work of Stivers and Rossano (2010), who use Conversation Analysis to identify the elements a speaker deploys in, as they put it, 'mobilising a response' from a potential interlocutor - doing more than merely summon attention, and requiring a certain kind of response. Obviously, potential recipients must be within sight or earshot, or otherwise be intersubjectively available; thereafter it is up to the initiator to make a bid for something to start. Stivers and Rossano, gathering together elements from the existing literature on conversational management, identify the features that put an interlocutor in a position where a response is expected: gaze and bodily orientation; lexico-morphosyntax, prosody, and epistemic asymmetry. Of these, not all are fully available to people with SPID. Nevertheless, research on the interactions of people with intellectual impairments (even severe ones) has found the CA perspective on such micro-elements of behaviour useful; see, for examples of work on people with ID's understanding of choices, Antaki, Finlay, Walton and Pate (2008, and Antaki, Finlay and Walton (2009); or work on their managing of instruction and directives, Antaki and Kent, 2012. For an overview on CA work with this vulnerable group in general, see Antaki and Wilkinson (2012).

If the person with impairments has some language abilities (as not all do), their command of vocabulary and prosody will be limited, as will be their command of morpho-syntactic form (interrogatives, declaratives and so on and here it's relevant that Sidnell, 2010 p 198 reports that Sacks suggests that most "pick-ups" are in question format). That is to say, people with SPID may 
not have the capacity to find words and control grammatical form and intonation to specify that a response is wanted from the next speaker (let alone what kind of response). If they can vocalise at all, then the actual delivery of what they utter will often be unclear. The situation with epistemic asymmetry is still more cloudy. Epistemic status is the authority someone has to know about, and speak to, a given situation (Heritage 2012); where there is an epistemic imbalance between two people, the one with less "ownership" of the case will require response from the one with more (such that, for example, an apparent declarative "You're late" mobilises a response from the recipient, who can, and now ought, give the reasons). Given the intellectual limitations of people with SPID, the epistemic status of what they say (if it is intelligible) will be a very difficult matter to gauge, and may not reliably prompt a response in the same way as would an utterance by a neurotypical person. In sum: lexico-morphosyntax, prosody and epistemic status, are likely to be out of bounds for the person with SPID; it is gaze and posture (for which Kendon, 1990, gives a still-useful account; for a complete recent overview, see Nevile, 2015) which are likely to be the initiators most under the control of the person with SPID.

Our aim in what follows is to apply the insights of Conversation Analysis to recordings of everyday scenes in the lives of a sample of people with severe and profound intellectual disabilities, in order to examine exactly what resources they use, and the degree to which their use is reliant on the skills of their potential interlocutors.

\section{Data and Ethics}

Over about nine months, one of the authors $(\mathrm{CW}$, referred to as "Chris" in the transcripts) spent time in three residences as part of a nine month ethnographic study of National Health Service residential homes in the UK in 2008. One was a home for adults with comparatively less severe impairments 
(for details of interactions in that residence, see for example Antaki, Finlay and Walton, 2008). Another accommodated individuals with challenging behaviour, where permission to record eventually turned out not to be granted by staff. Our focus here is on "Ashgrove" ("Ashgrove") whose 10 adult residents, aged between 34 and 53 years, all had (according to their case files) an official label of severe or profound learning disabilities,. They all had significant communication difficulties and all, to differing degrees, depended on the staff for various aspects of intimate care on a day-to-day basis. The staffing level was four members per shift. Video recording was only introduced by $\mathrm{CW}$ after a period of establishing rapport with the residents and the roster of care staff.

The ethical procedures followed in the research were formulated in accordance with Department of Health guidelines for conducting research involving people with learning disabilities, and were approved by the NHS Central Office for Research Ethics Committee (now the National Research Ethics Service) ${ }^{1}$. We were mindful of variability in individuals' capacity to consent (though see Dye and Burton 2004 for a critique of this concept) and wherever possible we provided information about consenting to participate in the research in a form tailored to the individual's level of understanding.

The residents of Ashgrove, however, lacked the capacity for them to give informed consent in the usual meaning of the term. Instead we consulted with all interested parties (parents, relatives or legal guardians). All gave assent for further discussions to take place, bar the parents of one male resident; so he was never video- or audio-recorded. For the remaining residents, meetings involving the researcher, individual key workers, the home manager and any other interested parties were held to determine whether participation in the

\footnotetext{
1 This section covers some of the same material in the equivalent section of a previous article about this residence (Finlay et al, 2008), with modifications.
} 
research could in any way be contrary to the best interests of the resident. In all cases it was agreed that participation would not be contrary to their best interests and, in fact, might be directly beneficial to them by promoting improvement to the quality of support they received. From that point on, all but the one excluded resident were treated as participants in the research and their interactions with staff and other residents were amenable to videorecording. With regard to staff, six of the eight who were rostered to have duties at Ashgrove during the research period agreed to appear on the videos; two declined.

On all occasions when recording was to take place, the residents' reactions to the presence of the researcher and the camcorder were monitored by both the researcher and members of staff for any signs of distress; none were ever observed. In all other respects, the research conformed to usual ethical guidelines; recording did not take place in any situation that could be considered an invasion of privacy and the confidentiality and anonymity of the participants' contributions were respected and assured.

Videos were recorded in the public rooms and the garden of the residence (but not during meals in the dining room, as we felt that recording residents' difficulties with eating might prejudice their dignity) and on excursion to a local park. In many periods of the recordings, only the researcher $(\mathrm{CW})$ was present in the room with the residents, while staff went about their business elsewhere.

By dint of being present in and around the residents and staff as they went about their daily routines, CW shot forty periods of video, each on average about ten minutes long. That resulted in a little under seven hours of raw footage. The locations we recorded in were the public areas indoors, or bounded space outdoors, on the few occasions on which there was an excursion or the residents sat outside (the residence's garden, a picnic table in 
a park). Effort was made to take a reasonable sample of the life of the residence - staff escorting the residents around the building, providing them with snacks, engaging them in play or conversation, or leaving them in the public rooms while they attended to matters elsewhere - but decisions about the length of any particular recording were made ad hoc according to the contingencies of the situation.

Where there were opportunities for interaction, the camera stayed on. Some episodes of filming were short because interactions between staff and residents in the social shared spaces of the house were often brief and perfunctory; others were long when there were enough people in the room (residents, staff and / or the researcher) to give the residents an opportunity to initiate something. Here CW made a local decision of how much to film, and would end the filming if the situation promised no more likelihood of action (e.g. if most residents had retired to their rooms, or when those remaining were obviously somnolent, and no staff were present). Recordings could be, and sometimes were, temporarily interrupted or wholly curtailed by the presence of a member of staff or a resident for whom we did not have consent to record.

For a group of neurotypical adults, this sample of occasions and venues would have afforded ample time for a large number of initiations of interaction among themselves, or with staff or the researcher. The residents in Ashgrove, however, spent most of their time disengaged from others in their environment, either occupied in repetitive behaviour, or sitting or lying still. So the initiations that we saw were rare.

\section{Analysis}


Following the methods of previous Conversation-Analytic research on people with intellectual impairment (and the field stretches back to Yearley and Brewer, 1989; for a recent overview, see Antaki and Wilkinson, 2012) we approached the data in bottom-up fashion, paying close attention to the detailed sequence of turns by which the participants built their interactions. Working inductively from the data rather than from a pre-ordained category system, we found three main types of initiation-encounter, which we list below. We then offer examples of each one, detailing the interactional practices involved.

1) Sustained initiations, of two broad kinds:

- Inaugurating a new activity. In such cases, the resident made a move that successfully began, and sustained, an interaction where there was none before.

- Initiations of a change in the direction of an on-going trajectory; this could be a comparatively minor (but still discernible) shift in the activity (e.g. indicating that a chair be moved before being helped down onto it by the support worker) or even a complete about-face (for example, refusing to sit down at all, and leading the support worker off somewhere else). In both cases, the new trajectory was sustained by the resident. ${ }^{2}$

2) Unsustained initiations. On occasion, a resident would issue what was taken by an interlocutor (a staff member or, more usually, the researcher, CW) to be the initiation of an interaction; but the interlocutor's response was met

\footnotetext{
2 Note that our interest here is in initiating turns that project positive further turns from the interlocutor, so we shan't report on outright mute resistance (which did sometimes occur in the residence) since, on those occasions no response from the interlocutor was wanted other than that they left the resident alone - such moves were terminations, not initiations, of an interaction.
} 
with no discernible acknowledgment or further move on the part of the resident.

3) Blank Recipiency. These were cases of the residnet making themselves available to receive another person's first explicit move in a conversation - but only minimally, with no positive indication (not even an ambiguous one) of what would count as such a move.

In cases (1) and (2) above, the resident did something over and above mere presence (be it a vocalisation, a direction of gaze, or a touch), which, ambiguous or not, meant that there was at least something for the interlocutor to go on; in the cases of blank recipiency in (3), there wasn't. We should note that the distinction between this kind of a case - where the resident merely presents themselves for interaction - and a resident positively, if ambiguously, initiating a move or a shift, was difficult to draw securely. Nevertheless it is worth trying to keep the dividing line between them, because, as we shall see, there are implications for what the interlocutor is to do next.

\section{A rough count, and a caution}

In terms of a simple count of their initiations of engagement, we captured: four attempts at interaction that were sustained beyond the first pair of utterances; 12 unsustained attempts; five initiations of change in an ongoing interaction; and five cases of blank recipiency. So in a little over seven hours of possible interaction across about 40 days, there were 26 attempts by a resident at starting an engagement, sustaining four beyond the initial move. In other words, the video sample reflected the ethnographic impression of what went on in the residence - aside from activity generated by the staff, residents had long periods of disengagement, punctuated by them only very occasionally essaying initiation. 
How useful are these figures? As noted in the Data section above, these interactions come from one residential service for a small number of people with SPID in England. The appearance of any one episode of an interactional practice will have been a product of operational factors (e.g. whether the camera was on at the time and the person in shot; the time of day and the venue of the recording; and so on) and a number of factors specific to the nature of the service and the service users: the degree and nature of the person's impairment (e.g. whether it included sensory and motor impairments); the opportunities for interaction (e.g. the availability of interlocutors (especially staff) in the room); the training of the staff members; and perhaps even the overarching 'mission statement' of the Trust in which the service was located, and the degree to which it encouraged staff-resident interaction, provided activities which allowed joint action, and so on. To this we may add that two members of staff chose not to appear on camera, and one resident was excluded on his parents' wishes; so any idiosyncratic practices may have escaped notice.

Having said that, we feel confident that the particular service provider was not untypical of such services in the UK, and that the practices shown by the residents seemed sufficiently recurrent as to suggest - though we make no claims about their frequency - that they were reasonably representative of practices that persons with a range of severe and profound intellectual impairments could and do use to engage with those around them.

\section{$\underline{1 . S u s t a i n e d ~ a t t e m p t s ~ a t ~ i n i t i a t i o n ~}$}

A resident could use vocalisation, gaze and gesture to initiate an interaction from scratch, and to demonstrate their interest in engagement by pursuing it once the exchange was underway. Equally, they could use their resources to initiate a categorical shift in the trajectory of an interaction that was already in train, having been started by another person (usually a member of staff). We 
report these separately, making clear the unfolding sequence in each episode (unlike the previous, more static and category-based research we reported on in the Introduction).

\section{a) Initiating a fresh, sustained episode of interaction}

Example 1 shows the resident deploying posture, gaze, vocalisation and gesture; example 2 shows a resident using posture, gaze and touch. In both cases, the resident sustains the interaction beyond their first move.

\section{Example 1. Ashgrove V26 min 11.20: Matthew in park ${ }^{3}$}

Six residents, two support workers and one of the authors (CW, doing the filming) are sitting around, or near, a picnic table. Preceded by no other utterance, Matthew looks up at a support worker (SW1) - out of shot - and utters a two-syllable sound, possibly a try at a word.

01 Matt (nye:hnyeh), ((then drops gaze))

02 SW1 what darli:ng.

03

04 SW1 >what d'y want.<

05

06 SW1 hah?

07

(2.0, in which Matt looks up briefly)

08 SW1 (>havin' a $<$ nice ti.me)?

09

(3.00 (in which Matt looks up \& raises his right hand towards SW1)

11 SW1 > what $\mathrm{d}^{\prime} \mathrm{y}<$ want.

(10.0 in which Matt looks down $\mathcal{E}$ away and returns to)

${ }^{3}$ All residents' names are pseudonyms 
In the video, we can't see the support worker, but her immediate reply to Matthew shows that she, at least, takes it that he is directing his gaze - and his talk - at her. His actions meet two of Stivers and Rossano's (2010) criteria for mobilising a response from an interlocutor - gaze and vocalisation. But note that what Matthew says is not easy to evaluate using neuro-typical standards of prosody (his turn ended with continuing intonation, which usually signals that there is more to come; but did he intend that?) let alone morpho-syntactic design (was his utterance syntactically a declarative, an interrogative...?). Without such guidance as to which specific first-pair part is intended (that is, what Matthew intends to stand as an utterance which projects a given class of next response as a second part of an established pair, like a question-answer or summons-response pair) the support worker falls back on "what darling" (line 2). This is what Drew (1997) calls an open-class repair initiator - that is, it is a signal that what the previous speaker has said is radically ambiguous, or that the speaker means to claim that it is.

The interactional difficulty now, however, is that this places back onto Matthew the burden of continuing by specifying what it is he wants (more technically: specifying what kind of response would count as an appropriate next turn from his interlocutor; Schegloff, 2007) - and he is apparently unable or unwilling to take it. He carries the interaction no further at that point (line 3) or at the SW's prompt at line 4, which is an attempt to cast Matthew's utterance as indicating some kind of need (and so make the class of what she would be expected to do more obvious, e.g. provide him with a drink, and so on). This fails; but note that Matthew does issue two further positive contributions, both apparently still oriented to the support worker; an upward look in line 7 and a look and marked gesture in lines 9-10. Both are, again, hard to interpret; but they seem to denote an attempt by Matthew to keep the interaction going. In response, SW1 makes five attempts to solicit 
specific kinds of turns from Matthew, but none are successful, and although the interaction is sustained, it remains unclear what Matthew means.

\section{Example 2: Ashgrove - VD27 2.35 - 11.35 Jay tapping}

In this episode, a resident (Jay) makes multiple attempts to engage another in interaction (we should note that this was very unusual; what few attempts at initiation there were on all but two occasions directed towards staff or the researcher). Although he has some (non-lexical) vocal control, all his turns in this episode are non-verbal, relying on gaze, body orientation and touch.

Given the nature of the episode, a narrative illustrated by an image is more informative than a transcript. Hannah is seated on the left of a two-seater sofa in the living room, not engaged with any of the other residents in the room. Jay is in a separate part of the room busy manipulating objects (mostly plastic toys) in a large box - a habitual practice. He takes this box across to the sofa and sits down next to Hannah. In dropping onto the sofa, he looks down and to his right, at Hannah's leg, and reaches down to pat her thigh twice. Hannah does not respond or alter her position, slumped, facing forwards, arms crossed. (Figure 1). Jay has deployed two modalities (gaze and touch) on this first attempt at initiation; in eight subsequent re-issues over the next 11 minutes, he once more uses both modalities together and on the other seven attempts he either gazes or taps. So although he sustains his attempts at initiation over multiple turns, all are unsuccessful, even at the basic level of getting his would-be interlocutor to engage visually with him. 


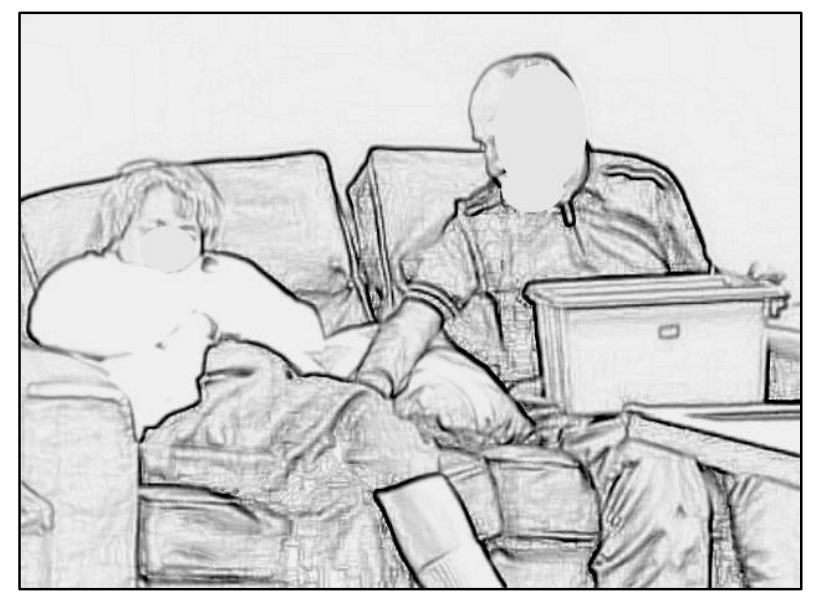

Figure 1: Jay looks down and pats Hannah's leg, but gets no response

Unlike Matthew in Example 1 above, Jay deploys a combination of elements which, in neuro-typical interaction, would guarantee a response by the recipient (- or more accurately, which otherwise would incur the penalty of seeming to be deliberately un-cooperative; compare the under-resourced attempts to solicit a response documented by Stivers and Rossano, 2010). Were Hannah to have responded, we might have seen an extended interaction - but she does not. Whatever Jay's intentions in beginning the engagement - a request to Hannah to look at his toys, an enquiry about her well-being, or simply an invitation to share some intersubjective time - they were frustrated. So both Matthew's and Jay's attempts to initiate something came to no satisfactory conclusion, but for different reasons: in Jay's case because his interlocutor was unable or unwilling to comply, and in Matthew's case because his utterances, though in the appropriate sequential positions, did not give enough direction to his interlocutor.

\section{b). Initiating a change in current proceedings.}

In these cases, the resident effected a change or re-direction in some on-going interaction. These cases are not the same as occasions on which residents simply terminated an activity, which we don't consider in this article (but see a case of sit-down passive resistance in Finlay et al, 2008b). Point-blank resistance is as it were unilateral, insofar as it projects no uptake from the 
interlocutor beyond stopping doing something (for example, giving up making the resident stand on weighing scales; in such cases the resident may simply stand their ground, or drop to the floor, as in Finlay et al 2008b). The cases we have in sight here are those that propose an alternative trajectory to the activity, which entail more than a one-off action on the interlocutor's part; they foresee some extended progression involving at least one further exchange of turns. In example 3 below, resident David interrupts a support worker's leading him to a chair in order (as it transpires) to go elsewhere.

\section{Example 3. Ashgrove VD18 minute 7.30 David, nice drink}

$01 \quad$ [(SW2 leads David into room, his arm hooked in hers $))]$

02 SW2 [come an' sit down I've got nice drink for you:.

04 SW2 [would you like an ap- (.) what d'y want.

05 Dav [((brings right arm up to grasp and restrain SW2's holding arm, 06 while pulling back away from direction of travel

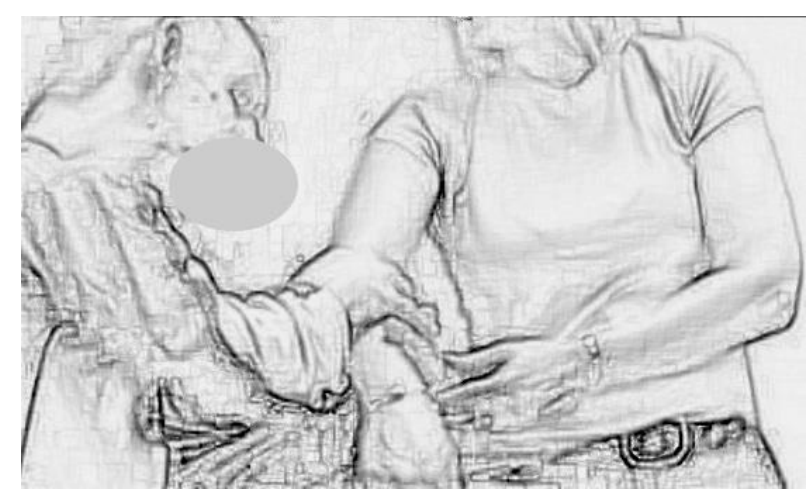

Figure 2 - David (left) uses his right hand to restrain SW2's progress

$08 \quad[(($ David pulls SW2 back the way they came; she follows him $))$

09 SW2 o:kay, (.3) let's go this way then. 
Although what David initiates is not a verbal interaction, if we take the SW's shepherding him to one chair as a first move, what he is doing is counterproposing a distinct alternative first move; not resisting full stop with no indication of an alternative, but issuing a turn which itself projects and requires uptake from the $S W$ - specifically, compliance with his indication that he wants to go somewhere other than where she's leading. His deployment of touch, gaze and body movement is successful, and prompts (line 4) the support worker to solicit another meaningful turn from him. His move back toward the centre of the room is taken by the support worker as a deliberate decision by treating it as a proposal to comply with (line 9 - okay, let's go this way then).

If we contrast this case with Matthew's apparently unsatisfactory episode with his support worker (Example 1 above), then it is tempting to attribute the success here to the fact that David's pull at the SW takes place in an ongoing interaction the meaning of which has already been established. He is being taken towards a specific seat for a specific purpose, so a pull at the SW's arm can be understood as not a random movement but a pull away from a destination and towards another one; that is, as an alternative that requires compliance. His turn takes on local significance afforded by a context that the interlocutor has equal access to. This a clear contrast to all our other cases, where the interlocutor's engagement has to be guessed at from inadequate evidence - and fails. If any attempts by residents can be said to succeed in beginning an episode of interaction intelligible to, and successfully sustained by, both parties, it is this one.

\section{Unsustained initations}

On many occasions, the resident's interlocutor treated what the resident had just said or done as being an initiation (even though it lacked some, or many, 
elements of the response-mobilising features identified in Stivers and Rossano, 2010), but the resident made no subsequent move, and the interaction ran into the sand.

a) An apparently clear use of gaze and body posture. In the example below, we see a resident offering a candidate initiation in the form of extending a hand, with visual and bodily orientation to the possible recipient. Her interlocutor does make a response; but thereafter, she does not provide any further contribution to the interaction.

Example 6. Ashgrove VD11 4.55 Tina "Stones"

Some residents are in the garden. Chris moves towards Tina, who is standing by a raised flowerbed. As he approaches, she holds out her hand, palm up (line 1). There is nothing in that hand, but her other hand is holding small stones.

01 Lisa ((looking up at Chris, extends right hand palm up and empty)).

02 Chris ((takes her hand))

03

04 Chris what.

05

06 Chris nuh 'at's just pebbles, (.8) y've not to eat them though.

(7.0) ((in which Tina's head comes into frame bending

08 ((down to pick somehting up with her right hand))

09 Chris Tina.

11 Chris You've not to eat the things you pick upp.

Tina's open, palm-up hand at line 1 is obviously directed at the approaching Chris, who takes it in his own hand. At this point the camera is pointing downwards towards their hands, so we don't see Tina's face; but she makes 
no vocal sound. Chris issues an open-class repair initiator, as does the interlocutor in Example 1, and for the same reason: the opacity of Tina's first move, and the lack of any follow-up to Chris's response (taking her hand). Chris pursues a didactic line in the absence of any clue as to what Tina is intending, and when her face reappears in the frame she has no discernible expression nor is her gaze directed at Chris. The interaction peters out with no further contribution from her.

b) A vocalisation and brief glance. In our final example, the resident makes a sound (which we describe as a "yelp") and looks toward the interlocutor (again, the researcher $\mathrm{CW}$ ) but only very briefly.

\section{Example 7 Ashgrove VD 22 Jay "yelp"}

Jay is sitting at a dining table with some other residents; Chris moves to sit behind him with the camera. Around 30 seconds later Jay turns his trunk and his eyes dart up to look just above the camera, where Chris's face would be, and then immediately back down. As his eyes move down Jay vocalises (with a 'yelp') and after a tiny pause turns fully away back to home position at the table. Chris laughs and responds what'd you say Jay? Jay turns and looks again, very briefly, in Chris's direction; but he immediately turns back to the table again and issues no further sound or gesture in Chris's direction.

Jay often does vocalise with this kind of yelp - apparently unilaterally, without direction or intended recipient; so the yelp by itself is ambiguous. What perhaps Chris is responding to is the yelp plus bodily orientation. However, Jay doesn't maintain his orientation - he turns away, and issues no response to Chris's verbalised open-class repair invitation. If Chris was right to treat what Jay did as an the initiation of a sequence of actions, it was not sustained. Like the episode in Example 6, an interlocutor has noticed something about the resident's behaviour which, thought it lacks the complete 
range of evidence normally given by language use, gaze and body movement, is much more than blank presence (as we shall see below), and seems to warrant treating as a possible initiation. The interlocutor issues a 'response' in example 6, a candidate formulation of what the resident said; in 7, an openclass repair initiator - but, as in the majority of other cases, the resident makes no further contribution.

\section{Blank Recipiency}

In this section we describe how a resident initiated an interaction not by a positive first turn, but by making themselves explicitly available for receiving such a turn from an interlocutor. What we have in our sights here is the case where the initiator does no more than signal readiness for interaction in some bodily way, without making any indication of what the nature of the interaction should be. The positive part of the definition is that, out of no ongoing interaction, the person's body has to be manoeuvred explicitly into a position which brings them into, or marks them as, now in intersubjective sensory space with a given interlocutor (walking up them and gazing at them; turning to them and leaving towards them; and so on). The negative part is that the person does no more than this - that there is no current activity that gives this move meaning; and that there is no vocalisation or gesture which could (straightforwardly or generously) be interpreted as freighted with meaning. So that would exclude for example, David's pull at SW's arm (which comes in an ongoing interaction), and also Matthew's "nye:hnyeh" which, although hard to understand, is at least a positive attempt to express something which could indicate a topic or activity to be further expanded (or could be taken to be so).

More technically, the difference between indicating recipiency and an explicit action of initiation (by gesture or vocalisation) is that the latter is (or can be understood to be, if generously interpreted) a first pair part that stipulates 
what the class of next turn should be. Just indicating that you are ready to allow the other person to begin requires them, if the interaction is to maintain progressivity, to creatively imagine a possible first pair part on your behalf - a very unusual situation among people with neurotypical capacity, and probably experienced by the interlocutor as challenging to some degree.

Cases which meet our definition of marked sensory availability are, however, always liable to be ambiguous. In the example below, it is difficult to determine whether the resident is seeking a turn by her potential interlocutor, or that if she is approaching and looking at him simply because she is interested in what they see. But what we can rely on is the interlocutor's behaviour - he, at least, treats her actions are implying a wish to engage.

\section{Example 4: Hannah approaches Chris VD 25 min 00.30}

This wordless episode, like Example 3 above, is better reported as a narrative plus illustration, rather than transcript. The video recording opens with Hannah standing in the centre of the picture in the living room, a few feet from the camera. She has one arm wrapped around her torso and the other folded up to her shoulder. Her face and gaze are generally directed downwards; but on four separate occasions she looks up directly at Chris, who is a few feet away, holding the camera on his lap, pointing towards her. Hannah then turns and walks towards Chris, but somewhat to his left and out of shot. At this point Chris asks "what's up Hannah?" to which she gives no response. As the camera pans left to locate her, Hannah's head and torso come back into shot. She is standing slightly to the left of Chris and looking directly down at him (figure 3). As far as we can tell, her gaze is directed to his eyes, not to the camera, which is on his lap, pointing upward. 


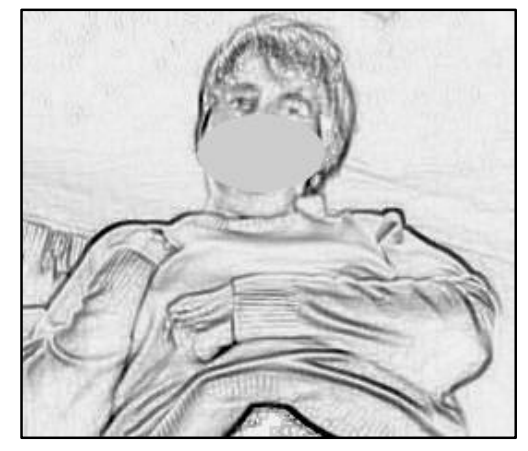

Figure 3. Hannah stands directly in front of interlocutor, gazing down at him

Hannah's blank recipiency allows the greatest possible range for her interlocutor to determine how the interaction will proceed - but, equally, gives no hint as to what direction she would favour. Chris treats her recipiency as a prompt to explain what he's holding: "'s a camera. I'll show you". (Note that the camera is on his knee, the viewfinder screen allowing him to keep his gaze free). Hannah still does not respond. After 10 seconds Hannah begins to rock, looking away and around the room and then back to Chris for 5 seconds. The camera then pans away from Hannah and the episode ends.

In the next example, we see a highly unusual case in which a resident displays recipiency to another resident - as we have noted above, resident-resident interaction of any sort was extremely rare.

Example 5. Ashgrove VD20 Barbara and Matthew, living room.

Five residents and the researcher are in the living room. Barbara walks over to Matthew, who is sitting on the floor. He does not look at her. She settles down cross-legged, oriented towards him, about a metre away, and leans towards him and gazes at him (see figure 4; Barbara on the right of the image) for about 2 seconds. She looks away briefly (.3 secs) while leaning back, then resumes her forward stance and her gaze towards Matthew for about 8 seconds. 


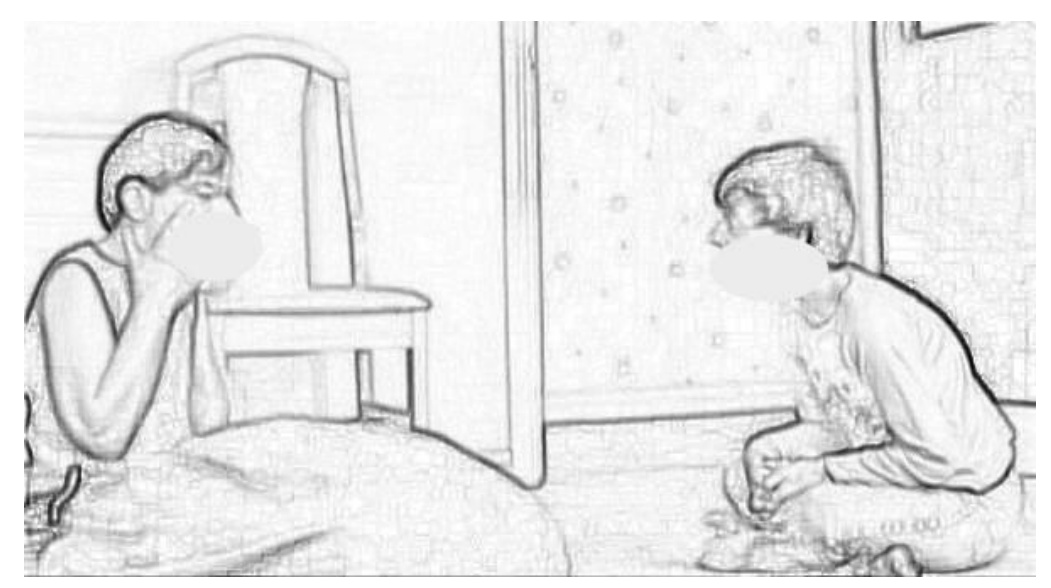

Figure 4: Barbara leans and gazes fixedly towards Matthew

At this point she makes a small mouth movement, turns her head slightly to her left, and begins peeling a piece of fruit she is holding. At no point does Matthew look directly at her, or give any other indication of engagement.

\section{$\underline{\text { Discussion }}$}

The aim of this study was to apply the methods of Conversation Analysis to the behaviour of people with severe or profound intellectual disabilities which either had the characteristics of initiations, or which were treated as initiations despite lacking the usual elements of such turns. In seven hours of video-taped everyday scenes in an English residential service, we found that among ten adults there were very few attempted initiations, most of which were unsustained. The only ones that seemed to provide for an interaction intelligible to both parties were initiations of a new phase of an activity already in train. In other words, their efforts at establishing intersubjectivity with an interlocutor - whether in the sense of co-producing a series of turns at interaction (Schegloff, 1992) or joint attention (Trevarthen and Aitken 2001), let alone agreement on the meaning of words (Mori and Hayashi, 2006) largely failed. 
The sample was small, and the environment an institutional one (as would be the case in the lives of most people with such impairments). Those and many other contingencies limit the generalisability of our findings. For example, other people with similar impairments might live with their family, and different patterns might be seen in those environments. In this institutional setting, the count was low and might even have been inflated by the fact that the recorder, CW, was necessarily present in the room - both available for interaction (unlike the staff), and more likely (again unlike the staff, who were recorded only once doing this) to interpret residents' actions as a first move in a sequence and encourage further turns. Moreover, since the aim of the project was to record interaction, he tended to gravitate towards residents who showed some signs of activity, as opposed to the more somnolent or selfabsorbed ones; and that also will have inflated the figures.

Inflated or not, the figures are low compared to what one might have expected in seven-plus hours among neuro-typical adults; but given what we know of the engagement of people with severe and profound intellectual impairments with the world around them, this comes as no surprise. What is new is in the detail of their communicative attempts, how they are supported (or not) by those around them, and what communicational resources the latter can, or could, bring to bear on the case.

The residents, of necessity, bypassed the neurotypical resources of vocabulary, syntactic form, prosody and epistemic status (Stivers and Rossano, 2010), and instead used elements of vocalisation, gaze, body movement and posture to initiate engagement. However, these conversational practices faced two serious, and related, impediments to success: production and comprehension. In producing a first turn in a sequence of conversation, the few initiations that were offered were unspecific (vocalisations, even when recognisable as a word, were ill-formatted as opening utterances; gaze, 
though directed towards the interlocutor, was not accompanied by signals of what next action was appropriate; and so on - for discussions of the ambiguous nature of communication in those in this category see Forster \& Iacono, 2008; Grove et al, 1999; Zilber et al, 1994). What we termed "blank recipiency" was still more unspecific: here the resident confronted the potential interlocutor with a steady gaze, held apparently expectantly for many seconds, inviting a response - but gave no further hint as to what response it should be. Whatever means of engagement the residents attempted, however, caused difficulties to their interlocutors, and usually failed.

The only success - the only time we could be reasonably sure that a resident had established intersubjectivity with an interlocutor, gained an appropriate response, and (as the litmus test) offered a further, sustaining turn - was on occasions on which the resident initiated a change to the currently underway activity. In example 3, resident David pulled at the support worker's arm; had she not been shepherding him towards a seat (for a cup of tea), the situation would not have afforded her the means to interpret his action, and allowed her to tailor an appropriate reply (of acknowledging that that was not what he wanted); and her response would not itself in turn have been validated by David's subsequent pulling her towards another destination.

In all other cases, the care workers (and CW, the researcher) faced the dilemma of being placed in a position where a response seemed to be warranted/required, even though the resident's utterance gave them very little to go on. But they did say something. However, this required the resident to analyse what was said, and produce the appropriate next step in the conversational sequence - which their disabilities made a very hard task indeed. This was a dilemma the staff and CW solved by erring on the side of engagement. But, untrained in any specific procedures for engagement with people with such serious cognitive impairments, they necessarily fell back on 
using their ordinary skills of interaction. The problem, however, is that while these are effective for engaging with other neuro-typical people, they are not tuned to the needs and capacities of people with SPID. Deprived of 'normal' cues to how to deal with the resident's turn, interlocutors usually fell back on one of two responses: treating it as an utterance requiring (or deserving) repair; or treating it merely as a summons. Both are at the very minimum of presumption about what the initiator means (indeed, asking for a repair openly admits not knowing what they mean).

Treating it as a repair allowed the resident the opportunity to re-issue his or her initial utterance in more specific form; and to give them greatest leeway, the interlocutor usually used an open-class repair initiator (what and so on) Drew, 1997). Nevertheless, this comprehensively failed. Alternatively, the interlocutor could treat the resident's initiation as a summons; this allowed the interlocutor to issue go-aheads (Schegloff, 2007 pp 92-93) which might be simple uh-huhs and the like, or open-class repair initiators like what, darlin'? or what's up Hannah?. These presumed the least possible in the resident's initiation, and, like a repair initiator, would, normally, be enough to elicit a further turn from a neurotypical person (or, more accurately, it would render them liable to certain inferences if they did not produce it). But again it failed. In both cases, the disabilities of a person with SPID either precluded them cognitively processing such turns, or formulating a response to them.

Surveys of staff show that they are of course aware that they have communication difficulties with their clients (Dalton and Sweeney, 2013), in part because, as experienced commentators observe, "staff supporting people with severe and profound intellectual disabilities are often left to their own devices" (Mansell and Beadle Brown, 2012, p 14). Staff will have no formal guidance on recognising that they can't use what works on neurotypical adults, and must find other ways of communicating with people with SPID (Finlay et al, 2008; Zilber et al, 1994). It is just these issues which are addressed 
in communication training programmes for workers in support services (e.g. Dobson, Upadhyaya \& Stanley, 2002; Purcell, McConkey \& Morris, 2000).

This failure in marked contrast to the parents of the 'mentally-retarded' and deaf-blind children studied by Goode (1994). The parents, by dint of intimate familiarity with their children, vast amounts of information about what Goode calls "routine, layout, likes and dislikes, and the body" (1994, p 65), and deep funds of patient attentiveness, managed to engage with their children in a variety of non-canonical ways ${ }^{4}$ which would be alien to neuro-typical interaction. Indeed, Goode himself went further than some of the parents in abandoning his neurotypical habits, and engaging with one of the children in an intimate, tactile, whole-body way which it would be impossible for support workers, for legal reasons, even if they had the time and training.

Even at the level of deciphering their clients, unlike parents, support staff cannot not call on intimate knowledge of their clients to supplement the meagre (in neuro-typical terms) interactional information they offered. The staff had a working, institutionally-appropriate knowledge of their clients, but it seems to have been inadequate. They were also working under inauspicious conditions - poorly paid, liable to frequent job-turnover, obliged to consider health and safety as overriding priorities, and with the running of the residence's domestic arrangements a constant pressure. None of this was likely to redress their lack of communication training. The dilemma for staff is to be available for residents to initiate engagement, though aware that these initiations may well lead nowhere; or to do other, perhaps more urgent, parts of their job for which their training, and their ordinary everyday skills are better fitted. In resolving this dilemma, the interactional attempts of people

\footnotetext{
${ }^{4}$ Goode himself went to great lengths to establish engagement with the children, at one point making himself temporarily blind and deaf, in order to understand what their reliance on embodied communication might feel like (1994, pp 33-34)
} 
with severe and profound disabilities - in any case rare and fragile - may not be as well supported as they might be. 


\section{$\underline{\text { References }}$}

Antaki, C. (2012) Seven interactional benefits of physical tasks for adults with intellectual disabilities. Intellectual and Developmental Disabilities, 50, 311321

Antaki, C, Finlay, WML, and Walton, C. (2009) Choice for people with an intellectual impairment in official discourse and in practice. Journal of Policy and Practice in Intellectual Disabilities, 6(4) 260-266

Antaki, C. , Finlay, WML, Walton, C and Pate, L. (2008) Offering choice to people with an intellectual impairment: an interactional study. Journal of Intellectual Disability research, 52, 1165-1175

Antaki, C. and Kent, A. (2012) Telling people what to do (and, sometimes, why): contingency, entitlement and explanation in staff requests to adults with intellectual impairments. Journal of Pragmatics, 44, 876-889

Antaki, C. and Wilkinson R. (2012) Conversation Analysis and the Study of Atypical Populations. In T Stivers and J Sidnell (Eds.) Handbook of Conversation Analysis . Blackwell-Wiley, pp 533-550

American Psychiatric Association (2013). Diagnostic and Statistical Manual of Mental Disorders (Fifth ed.). Arlington, VA: American Psychiatric Publishing. pp. 5-25.

Coles, J. (2001) The Social Model of Disability: what does it mean for practice in services for people with learning difficulties? Disability and Society, 16, 501-10. 
Dalton C and Sweeney, J (2013) Communication supports in residential services for people with an intellectual disability. British Journal of Learning Disabilities, 41, 22-30

Dobson, S., Upadhyaya, S., \& Stanley, B. (2002). Using an interdisciplinary approach to training to develop the quality of communication with adults with profound learning disabilities by care staff. International Journal of Language E Communication Disorders, 37(1), 41-57.

Drew, P (1997) "Open" class repair initiators in response to sequential sources of troubles in conversation. Journal of Pragmatics, 28, 69-101

Dye, L. and Burton, M. (2004) Capacity to consent to participate in research a recontextualization, British Journal of Learning Disabilities, 32, 144-50.

Ellertsen, L-J (2014) Maintaining intersubjectivity when communication is challenging: hearing impairment and complex needs. Research on Language and Social Interaction, 47, 353-379

Goode, D (1994) A World without Words. Philadelphia: Temple University Press.

Finlay, WML, Antaki, C. , Walton, C and Stribling, P. (2008) The dilemma for staff in "playing a game" with people with a profound intellectual disability. Sociology of Health and Illness, 30, 531-549

Finlay, W M L, Antaki, C, Walton, C. (2008a) On not being noticed: learning disabilities and the non-vocal register. Intellectual and Developmental Disabilities: 45, 227-245. 
Finlay, W M L Antaki, C. and Walton, C. (2008b) Saying no to the staff - an analysis of refusals in a home for people with severe communication difficulties. Sociology of Health and Illness, , 30, 55-75.

Forster, S., \& Iacono, T. (2008). Disability support workers' experience of interaction with a person with profound intellectual disability. Journal of intellectual and developmental disability, 33(2), 137-147.

Goffman, E. (1971) Relations in public: microstudies of the public order. New York: Basic Books, 1971.

Goodley, D. (2001) 'Learning difficulties', the social model of disability and impairment: challenging epistemologies, Disability and Society, 16, 20731.

Grove, N., Bunning, K., Porter, J., \& Olsson, C. (1999). See what I mean: Interpreting the meaning of communication by people with severe and profound intellectual disabilities. Journal of applied research in intellectual disabilities, 12(3), 190-203.

Heritage, J. (2012) The epistemic engine: Sequence organization and territories of knowledge, Research on Language $\mathcal{E}$ Social Interaction 45/1:30-52

Hostyn, I., \& Maes, B. (2009). Interaction between persons with profound intellectual and multiple disabilities and their partners: A literature review. Journal of Intellectual and Developmental Disability, 34(4), 296-312.

Kendon, A (1990) Conducting Interaction: patterns of behaviour in focussed encounters. Cambridge: CUP 
Mansell, J and Beadle-Brown, J (2012) Active Support: enabling and empowering people with intellectual disabilities London and Philadelphia: Jessica Kingsley

McConkey, R., Morris, I., \& Purcell, M. (1999). Communications between staff and adults with intellectual disabilities in naturally occurring settings. Journal of Intellectual Disability Research, 43(3), 194-205.

Mori, J and Hayashi, M (2006) The achievement of intersubjectivity though embodied completion. Applied Linguistics, 27, 195-219

Nevile, M (2015) The embodied turn in Research on Language and Social Interaction. Research on Language and Social Interaction, 48, 121-151

Oliver, M. (1990). The politics of disablement. London: Macmillan

Porter, J., Ouvry, C., Morgan, M., \& Downs, C. (2001). Interpreting the communication of people with profound and multiple learning difficulties. British Journal of Learning Disabilities, 29(1), 12-16.

Prain, M., McVilly, K., Ramcharan, P., Currie, S., \& Reece, J. (2010). Observing the behaviour and interactions of adults with congenital deafblindness living in community residences. Journal of intellectual and developmental disability, 35(2), 82-91.

Purcell, Roy McConkey, Irene Morris, M. (2000). Staff communication with people with intellectual disabilities: the impact of a work-based training programme. International Journal of Language E Communication Disorders, 35(1), 147-158.

Sacks, H (1992) Lectures on Conversation. Oxford: Basil Blackwell 
Schegloff, E A (1992) Repair after next turn: the last structurally provided-for defence of intersubjectivity in conversation. American Journal of Sociology, 97, 1295-1345

Schegloff, E A (2007) Sequence Organisation in Interaction. Cambridge: CUP

Stivers, T, and Rossano, F (2010) Mobilizing response. Research on Language and Social Interaction 43, 3-31.

Trevarthen, C. and Aitken, K J (2001) Infant intersubjectivity: research, theory and clinical applications. Journal of Child Psychology and Psychiatry, 42, 348

Williams, V (2011) Disability and Discourse. Chichester: Wiley-Blackwell

World Health Organisation (WHO) International Classification of Diseases (ICD) http://www.who.int/classifications/icd/en/ (accessed August 24th 2015)

Yearley, S and Brewer, J D (1989) Stigma and conversational competence: a conversation analytic study of the mentally handicapped. Human Studies, 12, 97-115

Zilber, D., Shaddock, A., Dowse, L., Rawlings, M., Guggenheimer, S., \& Browne, F. (1994). Communication patterns in services for people with severe intellectual disabilities: Function, form and responsiveness. Australian Journal of human communication disorders, 22(1), 85-98. 
